\title{
TÉCNICAS DE COLORAÇÃO CROMOSSÔMICA PARA ESTÁGIOS ESPECÍFICOS DA MATURAÇÃO NUCLEAR DE OÓCITOS BOVINOS'
}

\author{
TECHNICS FOR STAINING CHROMOSOME IN SPECIFIC STAGES OF THE OOCYTE \\ NUCLEAR MATURATION IN THE BOVINE
}

\author{
André do Prado ${ }^{3} \quad$ Alexandre Valente $^{3}$ \\ Paulo Bayard Dias Gonçalves ${ }^{5}$
}

\section{RESUMO}

O presente trabalho foi conduzido com o objetivo de avaliar a eficácia de três técnicas de coloração nuclear de oócitos bovinos nos estágios de vesícula germinativa (VG), metáfase I (MI) e metáfase ॥ (MII). Nestes três estágios de maturação nuclear, os oócitos, sem as células do cumulus, foram fixados em ácido acético:metanol (1:3) em lâminas (fixados em lâmina e corados com lacmóide; FLL) ou placa de petri (fixados em placa e corados com lacmóide; FPL) e corados com lacmóide a 1\% em PBS (phosphate buffered saline). Os oócitos foram também distribuídos aleatoriamente a um terceiro grupo, no qual foram fixados em lâmina e corados com Giemsa (fixados em lâmina e corados com Giemsa; FLG). No estágio de VG, a percentagem de oócitos corretamente identificados no tratamento FLL $(93,5 \%)$ foi significativamente maior do que nos tratamentos FPL $\left(53,1 \% ; \chi^{2}=9,84\right.$; $p=0,0017)$ e FLG $\left(55,2 \% ; \chi^{2}=9,03 ; p=0,0027\right)$. No entanto, a proporção de oócitos nos estágios de MI e MII precisamente corados com a técnica FLL (MI 41,7\% e MII 41,9\%) foram estatisticamente inferiores do que aquelas observadas nos tratamentos FPL (MI 90,0\%, $\chi^{2}=13,25 ; p=0,0003$, e MII 92.8\%, $\chi^{2}=12,45 ; p=0,0004$ ) e FLG (MI 83,3\%, $\chi^{2}=10,69 ; p=0,0011$, e MII 89,7\%, $\left.\chi^{2}=12,24 ; p=0,0005\right)$. Assim sendo, os resultados demonstraram que a eficácia das técnicas de fixação e coloração dos oócitos bovinos depende do estágio de maturação nuclear que está em estudo.

\footnotetext{
${ }^{1}$ Este trabalho foi implementado com o suporte financeiro da Fundação de Amparo à Pesquisa do Estado do Rio Grande do Sul (FAPERGS). Departamento de Clínica de Grandes Animais, Universidade Federal de Santa Maria, 97119-900, Santa Maria-RS, Fax (055) 226-1975.

${ }^{2}$ Médico Veterinário, Aluno do Curso de Pós-Graduação, UFSM.

${ }^{3}$ Bolsista de Iniciação Científica do CNPq, UFSM.

${ }^{4}$ Médico Veterinário, Doutor, Professor Adjunto, UFSM.

${ }^{5}$ Médico Veterinário, PhD, Professor Adjunto, UFSM, autor para correspondência. 
Palavras-chave: oócitos, maturação nuclear, meiose, bovinos.

\section{SUMMARY}

This study was designed to determine the efficiency of three different technics for staining bovine oocyte in the germinal vesicle (GV), metafase I (MI) and metafase II (MII) stages. In these stages, oocytes without cumulus cells were fixed in acetic acid:methanol (1:3) either on slides (FLL) or in petri dishes (FPL) and stained with $1 \%$ of lacmoid in phosphate buffered saline (PBS). Also, the oocytes were randomized divided in a third treatment, in which they were fixed on slides immersed in acetic acid:methanol (1:3) and stained with Giemsa (FLG). In the GV stage, the percentage of oocytes accurately identified in the FLL (93.5\%) was significantly higher than in the FPL $\left(53.1 \% ; \chi^{2}=9.84 ; p=0.0017\right)$ and FLG $\left(55.2 \% ; \quad \chi^{2}=9.03 ; \quad p=0.0027\right)$ treatment groups. However, the proportion of oocytes in the MI and MII stages correctly stained with FLL technic (MI 41.7\% and MII 41.9\%) was statistically lower than that observed in the FPL (MI 90.0\%, $\chi^{2}=13.25 ; p=0.0003$, and MII 92.8\%, $\left.\chi^{2}=12.45 ; p=0.0004\right)$ and FLG (MI $83.3 \%, \chi^{2}=10.69 ; p=0.0011$, and MII 89.7\%, $\chi^{2}=12.24$; $\mathrm{p}=0.0005$ ) treatment groups. With these results, it can be established that the efficiency of the technic to fix and to stain bovine oocyte depends on the nuclear maturation stage to be investigated.

Key words: oocyte, nuclear maturation, meiosis, bovine.

\section{INTRODUÇÃO}

A visualização dos cromossomos se faz imprescindível em estudos de maturação nuclear in vitro em oócitos de mamíferos. Para isto têm sido desenvolvidas diferentes técnicas que inclui coloração dos oócitos para observação do núcleo em microscópio de contraste de fase ou em microscópio eletrônico. As técnicas que foram desenvolvidas para a coloração cromossômica basearam-se inicialmente em trabalhos realizados em camundongos (DONAHUE, 1968), sendo que as características do ooplasma deste roedor são totalmente diferentes daquelas encontradas em bovinos. A zona pelúcida do oócito de camundongo é mais facilmente digerida pelo ácido acético e o seu ooplasma é mais claro, o que facilita sua fixação e coloração para a visualização cromossômica. Desta maneira, as técnicas utilizadas para coloração nuclear necessitam ser melhor adaptadas para a espécie bovina. As técnicas para observação em contraste de fase tem em comum os passos de desnudamento dos oócitos, a fixação com ácido acético e metanol ou etanol em relação $1: 3$, que pode ser realizada sobre uma lâmina ou em uma placa de petri durante 24 horas, com posterior coloração com aceto orceina (SIRARD, 1988), lacmóide (SHYU, 1990) ou Giemsa (SÜSS et al., 1988).

Para a avaliação da maturação nuclear, as etapas geralmente mais usadas nos diferentes estudos são as de VG (que predomina nas primeiras $8 \mathrm{~h}$ de cultivo), MI (11 a 17h) e MII (após as 17h; SÜSS \& WÜTHRICH, 1985) devido aos diferentes mecanismos de regulação de cada um dos estágios (BORNSLAEGER et al., 1986).

A eficácia das técnicas utilizadas nem sempre é igual para os diferentes estágios de maturação nuclear. Neste sentido, o presente trabalho objetiva avaliar a eficácia destas técnicas em estágios específicos da maturação nuclear de oócitos bovinos.

\section{MATERIAL E MÉTODOS}

\section{Colheita e maturação dos oócitos.}

Um total de 133 ovários foram obtidos em um frigorífico distante a $22 \mathrm{~km}$ do laboratório, sendo transportados em garrafas térmicas com solução salina a $30^{\circ} \mathrm{C}$ contendo penicilina $(100 \mathrm{Ul} / \mathrm{ml})$ e estreptomicina $(950 \mu \mathrm{g} / \mathrm{ml})$. No laboratório, os ovários foram lavados três vezes com solução salina, sendo os folículos de $1-6 \mathrm{~mm}$, logo a seguir, aspirados com uma bomba de vácuo e transferidos para um tubo de ensaio, no qual foram mantidos no líquido folicular até o processamento. Um total de 325 oócitos foram divididos aleatoriamente em três diferentes tratamentos.

O primeiro tratamento foi processado logo após a colheita, sem cultivar, com o fim de observar VG. O segundo e o terceiro foram cultivados em TCM (Tissue Culture Medium)-199 modificado com 25mM de Hepes, 2,2mg/ml de bicarbonato de sódio e $3 \mathrm{mg} / \mathrm{ml}$ de albumina sérica bovina durante $14 \mathrm{~h}$ e $24 \mathrm{~h}$ respectivamente para observar os estágios de MI e MII. 
Técnicas de fixação e coloração dos oócitos.

1) Fixação em lâmina e coloração com lacmóide (FLL). Após a retirada das células do cumulus com uma micropipeta com diâmetro justamente maior que um oócito, os oócitos foram colocados entre lâmina e lamínula com um mínimo de líquido. As lâminas previamente desengorduradas tiveram as lamínulas fixadas com vaselina nas quatro pontas e apertadas suavemente até entrar em contato com os oócitos e logo após tiveram duas bordas coladas com cianoacrilato, sendo colocadas em ácido acético:metanol em relação 1:3 no mínimo por 24h. Após fixação, os oócitos foram corados com $1 \%$ de lacmóide em $45 \%$ de ácido acético em PBS permitindo a passagem do corante por capilaridade entre lâmina e lamínula pelas bordas não coladas, sendo a lamínula posteriormente selada com esmalte. As lâminas foram examinadas com o auxílio de um microscópio óptico equipado com contraste de fase com aumento de 200x a 1000x.

2) Fixação em placa e coloração com lacmóide (FPL): oócitos desnudados foram fixados numa placa de petri por um período de $12 \mathrm{~h}$. A seguir os oócitos foram transferidos para um tubo de Eppendorf de $1,5 \mathrm{ml}$ com $200 \mu \mathrm{l}$ do meio TCM-199 modificado e centrifugados a $15.550 \mathrm{~g}$ por 3 minutos. Os oócitos centrifugados foram colocados em lâmina e corados com lacmóide conforme técnica acima descrita.

3) Fixação em lâmina e coloração com Giemsa (FLG): os oócitos foram colocados por 10 minutos numa solução hipotônica de $\mathrm{KCl} 0,075 \mathrm{M}$, sendo logo a seguir colocados numa lâmina, retirado o excesso de líquido e adicionado ácido acético:metanol (1:3) a temperatura de $4^{\circ} \mathrm{C}$. Após secagem a $39^{\circ} \mathrm{C}$ em mesa térmica, as lâminas foram imersas no mesmo fixador a temperatura ambiente por um período mínimo de $3 \mathrm{~h}$. Posteriormente, as lâminas foram cobertas em Giemsa permanecendo por $8 \mathrm{~min}$. Após este período, o corante foi removido e as lâminas secadas ao ar. A seguir, os oócitos foram cobertos com lamínula, a qual foi fixada com esmalte e examinada com o auxílio de um microscópio com contraste de fase (200x a 1000x).

O número total de oócitos obtido em cada replicação foi dividido aleatoriamente nos três tratamentos. Assim, as técnicas foram implementadas simultaneamente para cada estágio de maturação nuclear. A análise estatística foi realizada pelo teste de quiquadrado $\left(\chi^{2}\right)$ utilizando o programa estatístico SAS (1988). Os resultados dos tratamentos foram comparados utilizando a análise de contraste do método dos mínimos quadrados ponderados no PROC CATMOD.

\section{RESULTADOS E DISCUSSÃO}

Dos 133 ovários utilizados neste estudo, foram obtidos 406 oócitos, dos quais foram cultivados 325 complexos cumulus-oócitos (CCOs). Estes CCOs permaneceram em líquido folicular até o momento de separá-los aleatoriamente aos três tratamentos visando a inibição do reinício da meiose. A meiose reinicia normalmente quando os oócitos são retirados do líquido folicular e cultivados em um meio que contenha as condições mínimas de $\mathrm{pH}$ e osmolaridade que mantenha sua viabilidade (BUCCIONE et al., 1990). Levando em consideração este fato, a quebra da VG teve início em momentos similares nos três grupos. Da mesma forma, os oócitos tiveram um período de cultivo similar nos diferentes tratamentos, o que evitou a fixação e coloração de oócitos em estágios distintos da maturação nuclear.

Nãn é do nosso conhecimento que estas três técnicas para o estudo da maturação nuclear, as quais tem eficácia díspar em relação ao estágio de meiose em que encontram-se os oócitos, tenhram sido avaliadas em um experimento desenhado com esta finalidade específica. A utilização de técnicas específicas para a identificação de diferentes estágios da divisão meiótica em oócito de bovinos possibilita estudos mais acurados do processo de maturação nuclear de oócitos nesta espécie animal.

A técnica de fixação em lâmina e coloração com lacmóide ou orceina tem sido largamente utilizada para o estudo da maturação nuclear de oócitos bovinos em estágio de MII (SHYU, 1990; SIRARD, 1988). No entanto, somente oócitos em estágio de VG foram identificados corretamente em uma percentagem satisfatória com esta técnica (Tabela 1; Figura 1). Nos demais estágios não se obteve uma visualização perfeita dos cromossomos e em uma pequena percentagem dos oócitos foi possível identificar o corpúsculo polar quando em MII.

A técnica de fixação em placa e coloração com lacmóide, que pouco tem sido descrita em experimentos implementados na espécie bovina, demonstrou ser ótima para os estágios de MI e MII (Tabela 2 e 3), sendo considerada fraca para o estágio de VG (Tabela 1). A visualização dos cromossomos foi alcançada em 90\% dos oócitos quando em MI (Figura 2) e em 92,8\% quando em MII, onde observou-se perfeitamente 0 corpúsculo polar nos oócitos em MII (Figura 3). Esta técnica também foi eficiente para os estágios intermediários como quando os oócitos encontravam-se em 
anáfase I (Figura 4). A centrifugação foi realizada na tentativa de tornar mais claro o ooplasma; no entanto, não foi observada uma diferença significativa entre oócitos centrifugados e não centrifugados (dados não apresentados), o que permite concluir que a centrifugação não é imprescindível para uma perfeita visualização dos cromossomos.

Tabela 1 - Fixação e coloração de oócitos bovinos no estágio de vesícula germinativa.

\begin{tabular}{lccc}
\hline & $\begin{array}{c}\text { Oócitos } \\
\text { fixados }\end{array}$ & $\begin{array}{r}\text { Oócitos com adequada } \\
\text { identificação nuclear }\end{array}$ \\
Técnica & $n$ & $n$ & $(\%)$ \\
\hline $\mathrm{FLL}^{1}$ & 31 & 29 & $(93,5)^{\mathrm{a}}$ \\
$\mathrm{FPL}^{2}$ & 33 & 17 & $(53,1)^{\mathrm{b}}$ \\
$\mathrm{FLG}^{3}$ & 35 & 16 & $(55,2)^{\mathrm{b}}$
\end{tabular}

Letras diferentes indicam diferenças estatísticas $\left(X^{2}=10,52\right.$; $p<0,005)$.

'Os oócitos foram fixados em lâmina e corados com lacmóide.

${ }^{2}$ Os oócitos foram fixados em placa e corados com lacmóide.

${ }^{3}$ Os oócitos foram fixados em lâmina e corados com Giemsa.

A técnica de romper a estrutura do oócito com uma solução hipotônica de $\mathrm{KCl}$ e fixar com ácido acético, expondo e facilitando a coloração dos cromossomos com Giemsa ou orceina, tem sido utilizada em alguns experimentos com oócitos bovinos (SÜSS et al., 1988; COSTA et al., 1993). Com estas técnicas têm sido descritos excelentes resultados na identificação de MI e MII. Em nosso laboratório, a tentativa de coloração de oócitos em estágio de VG com a utilização desta técnica não tem sido satisfatória. Neste experimento, a técnica de fixação em lâmina e coloração com Giemsa também foi ótima para corar oócitos nos estágios de MI (Figura 2) e MII (Figura 3; Tabelas 2 e 3). No entanto, com esta técnica observou-se uma baixa percentagem de corpúsculo polar em oócitos que encontravam-se em MII, mas permitiu uma avaliação mais precisa dos cromossomos, observação esta similar ao que foi descrito por COSTA et al., 1993.

Tendo como base a metodologia utilizada e os resultados obtidos, conclui-se que a melhor técnica para a visualização da VG é através da fixação em lâmina e sua coloração com lacmóide. Enquanto as técnicas de fixação em placa e fixação em lâmina com coloração com lacmóide e Giemsa respectivamente são ideais para os estágios de MI e MII. É importante salientar que oócitos fixados em lâmina e corados com

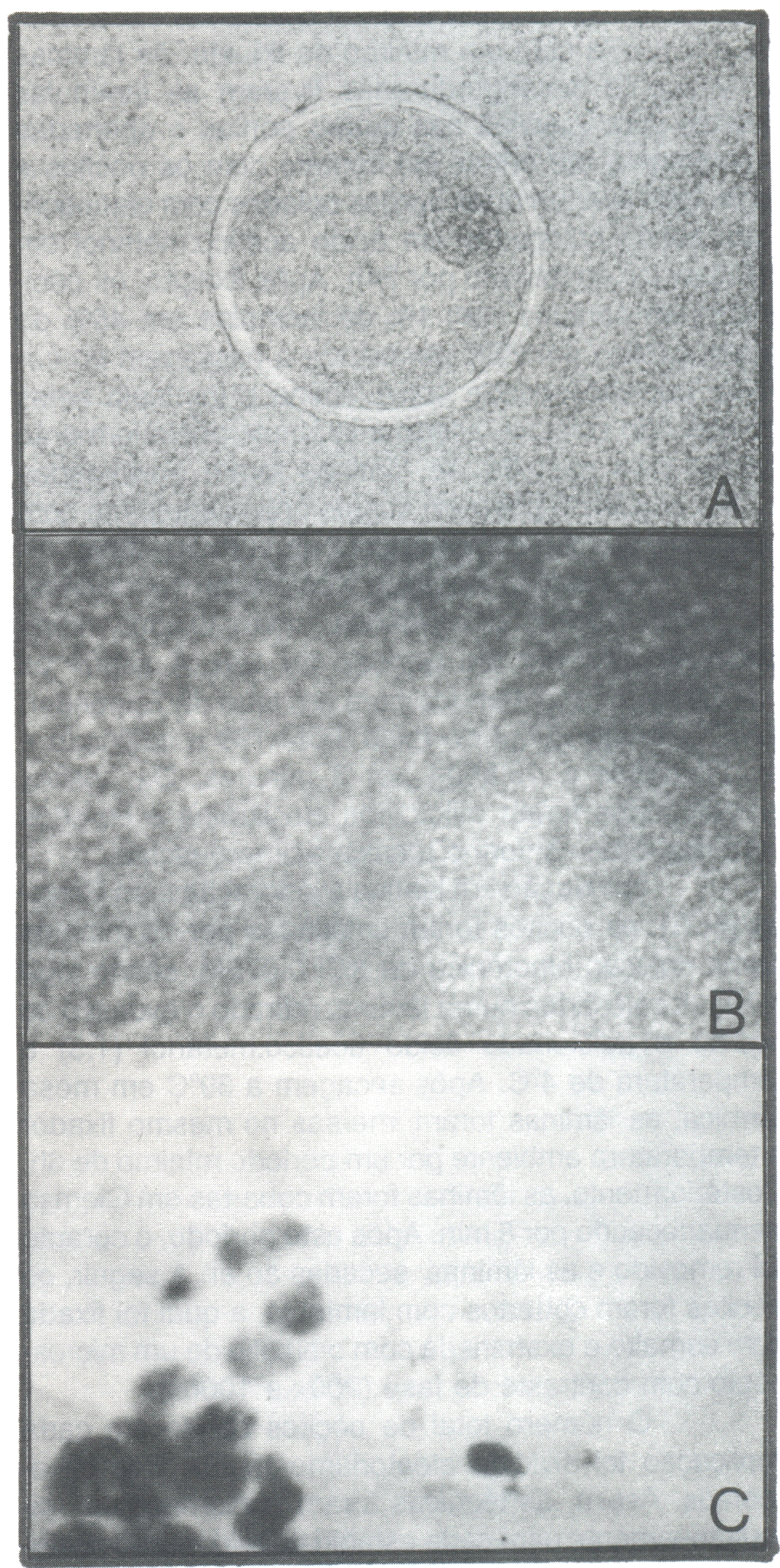

Figura 1 - Oócitos em estágio de vesícula germinativa, fixados e corados com os métodos FLL (fixado em lâmina e corado com lacmóide, A; 400x), FPL (fixado em placa e corado com lacmóide, B; 1000x) e FLG (fixado em lâmina e corado com Giemsa, C; 1000x). 
Giemsa perdem a sua estrutura morfológica, o que muitas vezes dificulta a observação do corpúsculo polar durante o estágio de MII e impede estudos que necessitem da integridade morfológica do oócito, como por exemplo, a observação da presença de espermatozóides no ooplasma para detectar fecundação ou polispermia, quando os oócitos são corados após o processo de fecundação in vitro.

Tabela 2 - Fixação e coloração de oócitos bovinos no estágio de metáfase I.

\begin{tabular}{lccc}
\hline & $\begin{array}{l}\text { Oócitos } \\
\text { fixados }\end{array}$ & \multicolumn{2}{c}{$\begin{array}{c}\text { Oócitos com adequada } \\
\text { identificação nuclear }\end{array}$} \\
Técnica & $n$ & $n$ & $(\%)$ \\
\hline $\mathrm{FLL}^{1}$ & 36 & 15 & $(41,7)^{\mathrm{a}}$ \\
$\mathrm{FPL}^{2}$ & 30 & 27 & $(90,0)^{\mathrm{B}}$ \\
$\mathrm{FLG}^{3}$ & 34 & 25 & $(83,3)^{3}$ \\
& & & \\
\hline
\end{tabular}

Letras diferentes indicam diferenças estatísticas $\left(X^{2}=18,80\right.$; $p<0,0001$ ).

${ }^{1}$ Os oócitos foram fixados em lâmina e corados com lacmóide. ${ }^{2}$ Os oócitos foram fixados em placa e corados com lacmóide.

${ }^{3}$ Os oócitos foram fixados em lâmina e corados com Giemsa.

Tabela 3 - Fixação e coloração de oócitos bovinos no estágio de metáfase II.

\begin{tabular}{lccc}
\hline & $\begin{array}{l}\text { Oócitos } \\
\text { fixados }\end{array}$ & \multicolumn{2}{c}{$\begin{array}{r}\text { Oocitos com adequada } \\
\text { identificação nuclear }\end{array}$} \\
Técnica & $n$ & - & $(\%)$ \\
\hline $\mathrm{FLL}^{1}$ & 31 & 13 & $(41,9)^{\mathrm{a}}$ \\
$\mathrm{FPL}^{2}$ & 30 & 26 & $(92,8)^{\mathrm{b}}$ \\
$\mathrm{FLG}^{3}$ & 33 & 26 & $(89,7)^{\mathrm{b}}$
\end{tabular}

Letras diferentes indicam diferenças estatísticas $\left(X^{2}=20,12\right.$; $\mathrm{p}<0,0001$ ).

${ }^{1}$ Os oócitos foram fixados em lâmina e corados com lacmóide.

${ }^{2}$ Os oócitos foram fixados em placa e corados com lacmóide.

${ }^{3}$ Os oócitos foram fixados em lâmina e corados com Giemsa.

\section{AGRADECIMENTOS}

Os autores agradecem ao Frigorifico Silva LTDA, sediado no município de Santa Maria, RS, pela gentil cedência dos ovários para a realização do presente trabalho.

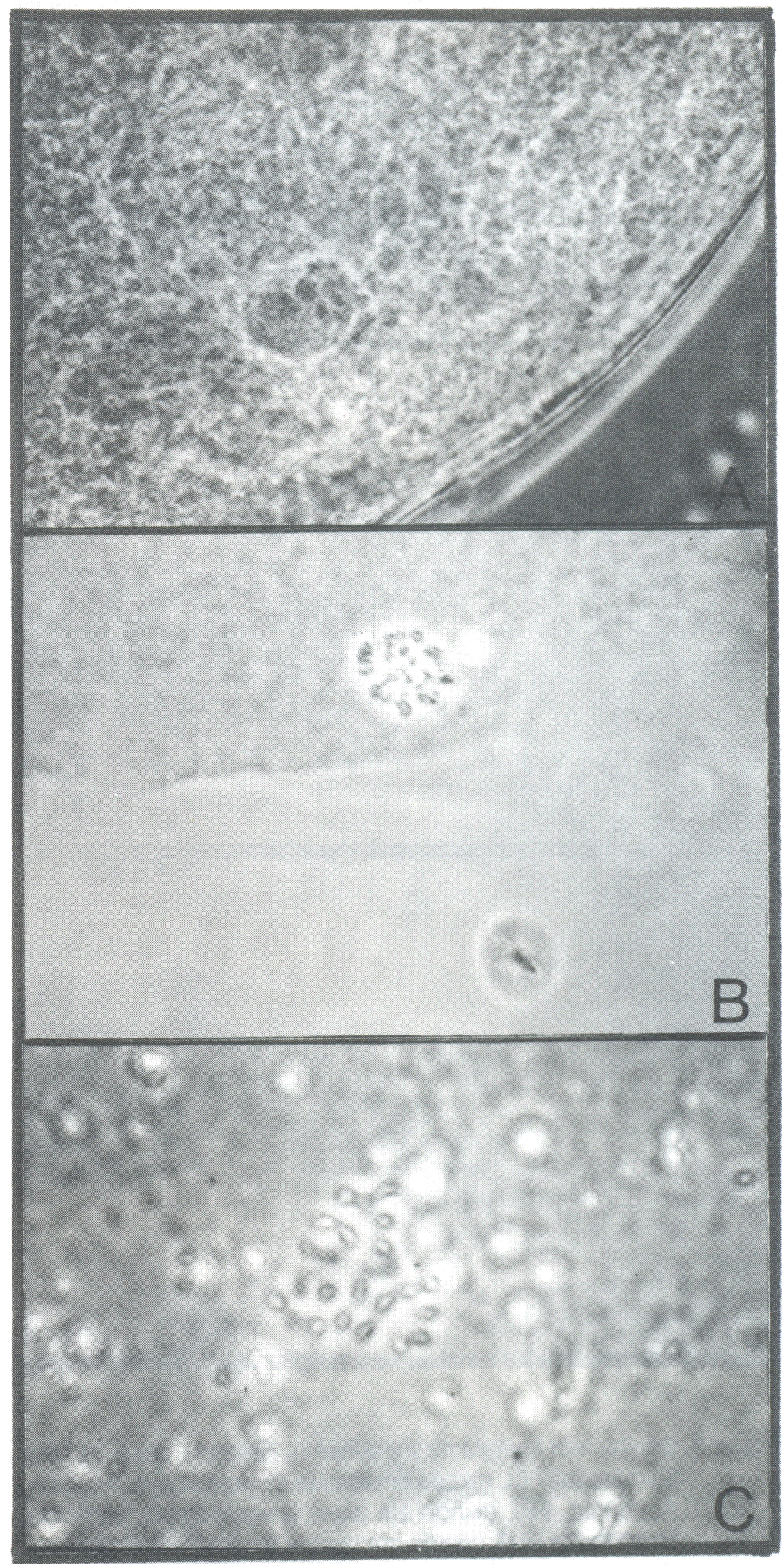

Figura 2. Oócitos em estágio de metáfase I, fixados e corados com os métodos FLL (fixado em lâmina e corado com lacmóide, A; 1000x). FPL (fixado em placa e corado com lacmóide, B; 1000x) e FLG (fixado em lâmina e corado com Giemsa, C; 1000x). 


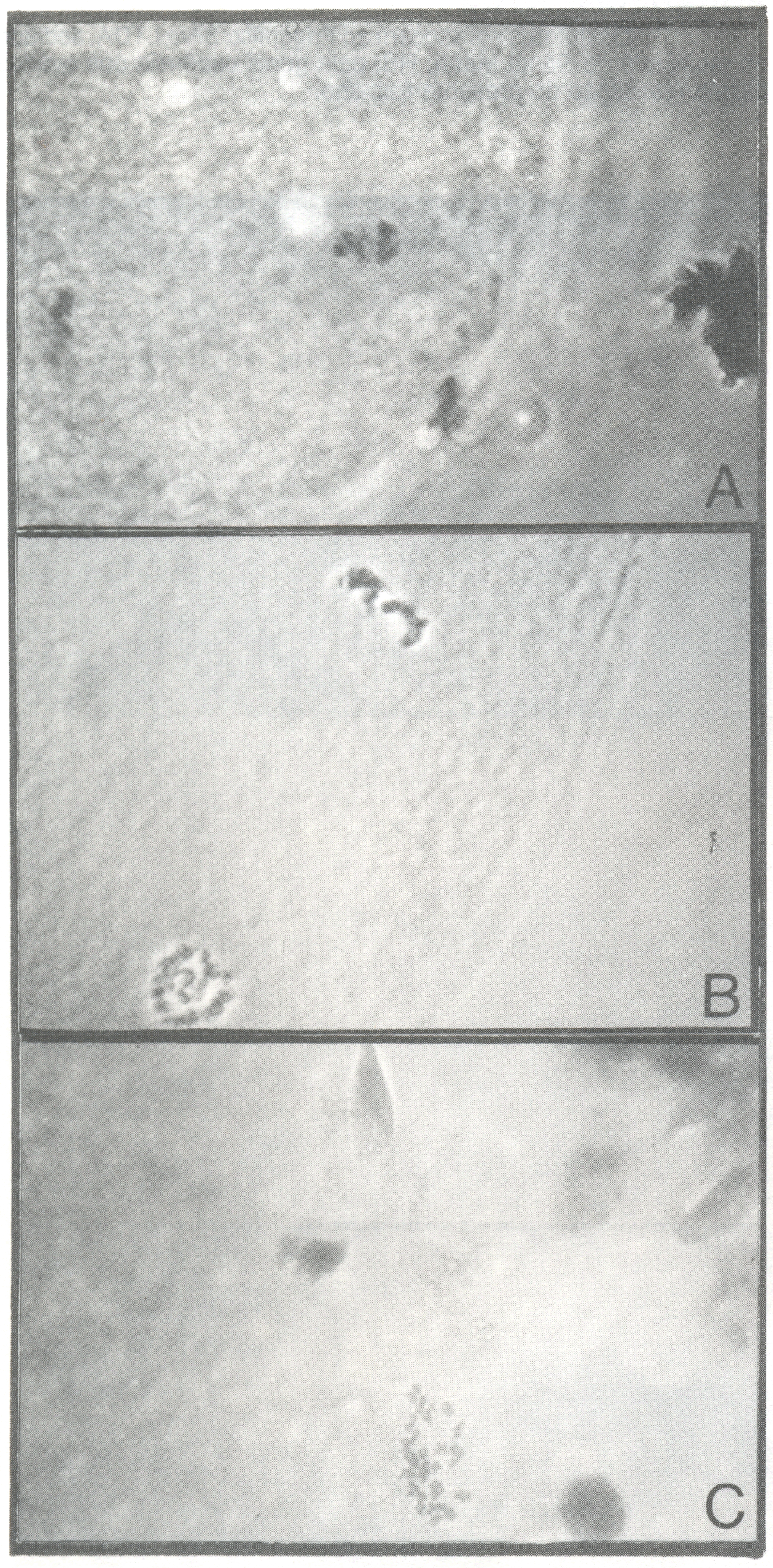

Figura 3. Obcitos em estágio de metáfase II, fixados e corados com os métodos FLL (fixado em lâmina e corado com lacmóide, A; 1000x), FPL (fixado em placa e corado com lacmóide, B; 1000x) e FLG (fixado em lâmina e corado com Giemsa, C; 1000x).

\section{REFERÊNCIAS BIBLIOGRÁFICAS}

BORNSLAEGER, E., POUEYMIROU, W., MATTEI, P., et al. Effects of Protein Kinase $\mathrm{C}$ activators on germinal vesicle breakdown and

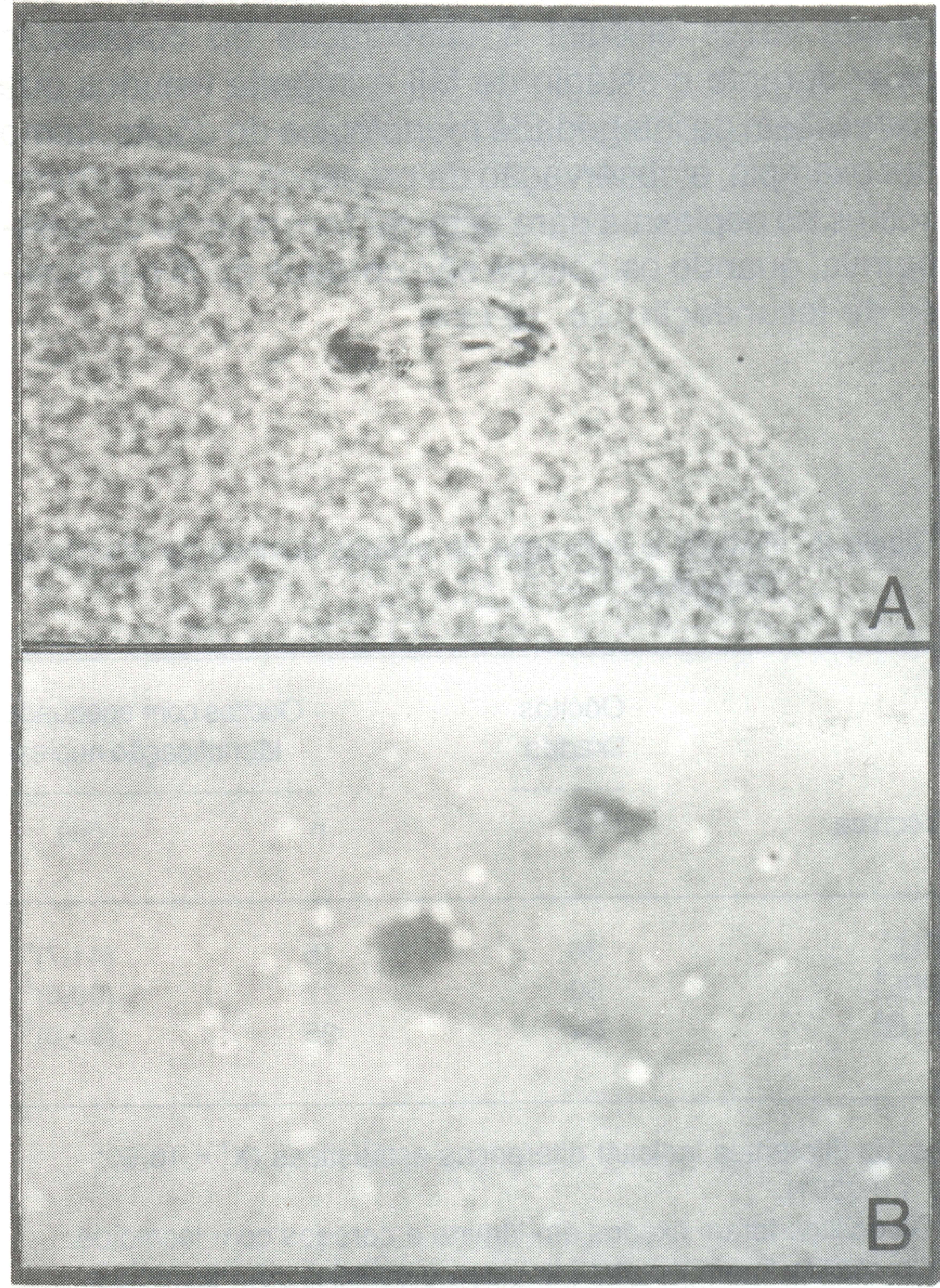

Figurra 4. Oócitos em estágio de anáfase I, fixados e corados com os métodos FPL (fixado em placa e corado com lacmóide, A; 1000x) e FLG (fixado em lâmina e corado com Giemsa, B; 1000x).

polar body emission of mouse oocytes. Exp Cell Res, v. 165, p. 507-517, 1986.

BUCCIONE, R., SCHROEDER, A., EPPIG, J. Interactions between somatics cells and germ cells throughout mammalian oogenesis. Biol Reprod, v. 43, p. 543-547, 1990.

COSTA, E.P., VALE FILHO, V.R., NOGUEIRA, J.C., et al. Técnica para a avaliação do estágio de maturação in vitro de oócitos de bovinos. IN: X CONGRES BRASILEIRO DE REPRODUÇÃO ANIMAL, 1993, Belo Horizonte; Anais... Belo Horizonte, Colégio Brasileiro de Reprodução Animal, 1993. v. 2, p. 200.

DONAHUE,R. Maturation of the mouse oocyte in vitro. Sequence and timing of nuclear progression. J Exp Zool; v. 169, p. 237-250, 1968.

SAS Statistical Analysis System. 6.03 ed. Cary, NC, USA: SAS Institute INC, 1988. $1028 \mathrm{p}$. 
SHYU, JEOU-JONG. In vitro maturation and fertilization of porcine oocytes and evaluation of male fertility. Urbana-Champaign, USA. Tese (PhD in Animal Science)-Course of Physiology of Reproduction. University of Illinois, 1990.

SIRARD, M.A., COHEN, K., BILOEDEAU, S. Effects of fresh or cultured follicular fractions on meiotic resumption in bovine oocytes. Theriogenology, v. 37, p. 39-57, 1988.
SÜSS, U., WÜTHRICH, K. Stages of the first meiotic division observed in bovine oocytes matured in vitro. Theriogenology, $\mathrm{v}$. 23, p. 231, 1985.

SÜSS, U., WÜTHRICH, K., STRANZINGER, G. Chromosome configurations and time sequence of the first meiotic division in bovine oocytes maturation in vitro. Biol Reprod, v. 38, p. 871$880,1988$. 